Four tubes developed in bulb broad bands of light yellowgreen electrical molecules, interspaced with darker bands; this was like the marking of the planet Jupiter.

Two tubes developed a mottled and leaf-patterned electricmolecular condition, extremely like the appearance of the photosphere of the sun (for the first time the skin of my hand was affected by one of these tubes-November 1896 ; this hand having some years previously had gouty eczema; the other hand was not affected in either case).

Two tubes developed forms like the clouds known as " mares'tails"; one tube, a form like the sulky lower strata of distant thunder-clouds.

The most interesting phenomenon was one which was also seen by a medical friend: the whole tube was a mass of yellowgreen phosphorescence, even behind the kathode ; the molecular film in glass bulb in front and round the edge of the kathode (mottled condition) developed a small black spot the size of a pin-head, which increased to the dimensions of a small pea, broadened out into an irregular patch, split up into small spots, which ran round the bulb, disappeared ; reformed into a patchdiminished-and disappeared. The phenomenon was repeated at regular intervals for ten minutes, then finally stopped. The irregular patch was extremely like a sun-spot.

From time to time I have called the attention of interested friends to the above phenomena, so as to have witnesses, as the tubes seldom repeat the same conditions, which can only be attained by the application of heat while working the tube.

The rays magnetised my watch on two occasions; an induction coil having no magnetic field, owing to interrupted current, could not do this.

Art Club, Blackheath.

\section{REMARKABLE TERMITE MOUNDS OF} AUSTRALIA.

THE destructive propensities and architectural endowments of the termites or white ants are familiar subjects to most travellers and residents in tropical countries. Notwithstanding, however, the almost cosmopolitan distribution within tropic areas of these insect pests, an astonishingly small amount of accurate data has been chronicled concerning their specific varieties or the widely varying modifications of their social tenements.

As a matter of fact the figures and descriptions of the insects and nest mounds or "termitaria" of the African white ants Termes bellicosus, T. mordax, and other species contributed by Henry Smeathman to the Transactions of the Royal Society for the year 178I, constitute up to the present date the standard account of white ants and their ways that is reproduced with trivial variations in most modern zoological text-books. Much, undoubtedly, has been accomplished within recent years, notably through the investigations of Grassi and Sandias, Fitz Müller, and other biologists to elucidate the minute anatomy, individual modifications, and social economy and relationships of the indigenous or imported South European types Termes incifugus and $T$. flavipes. Neither of these forms, however, are mound constructors, but live within subterranean tunnels or in excavations of the wood which they devour. Smeathman is hence still left, facile princeps, the first, almost the only authority on the architectural fabrications of the mound-constructing species.

While Africa in connection with Smeathman's investigations has hitherto inherited an undisputed monopoly in the matter of termite mounds, it will probably be found that the island continent of Australia can produce an equally, and in some respects even more noteworthy variety of these insect edifices. So far as altitude is concerned, the palm among the Australian series must be conceded to the huge buttressed columnar termitaria that occur some forty miles inland from Port Darwin in the Northern Territory of South Australia. A height of at least eighteen feet is not unfrequently attained by this variety, and their diameter being almost equal throughout, their appearance has been appropriately likened to miniature towers. Termitaria almost equal in altitude to this Port Darwin variety have also been observed by the writer in York Peninsula, North Queensland, and are notably abundant on the point of land abutting upon the mainland foreshore of the southern entrance to the Albany Pass. The largest termitaria of this type occur, however, in the vicinity of the bridle path between Mr. Frank Jardine's homestead at Somerset, and the former telegraph station at Patterson facing Endeavour Strait. Passing them on horseback, many of these mounds were observed to tower considerably above the rider's head. The contour of these York Peninsula termitaria differs essentially from that of the Port Darwin form. In place of being subcylindrical or columnar, they are distinctly pyramidal, widest at the base, and tapering up to a single, or it may be occasionally several accuminate points.

Within the tropical area of Western Australia, known as the Kimberley district of that colony, a third large and very distinct type of termitarium is dominant. While most commonly presenting a symmetrically conical or hemispherical contour, it not unfrequently happens that these white ant mounds are built up into the most irregular and fantastic shapes. Throughout all such innumerable modifications, however, one essentially unique fundamental plan of structure is predominant. This is exemplified by the circumstance that each nest mound or termitarium presents the appearance of having been built up, as it were, by the superposition of consecutive hod-loads of half solidified mortar, and which before setting has partly overflown and overlapped the preceding instalments.

This lobulated or Kimberley type of termite mound, as it may be designated, occurs in great abundance and in its finest development in the thinly wooded scrub or so-called "pindan" in the neighbourhood of Derby, at the head of King's Sound. One of the tallest of these termitaria was found to measure as much as fourteen feet, but this altitude is occasionally exceeded. The separate occasions on which the writer visited King's Sound were utilised by him for obtaining information concerning the approximate time that is occupied by the termites in the reconstruction of a partially dismantled edifice. Examples of termitaria about eight feet high were bisected vertically, the one half being completely demolished. Within twelve months one quarter of the denuded area had been filled in. Visited eighteen months later, fully two-thirds of the demolished moiety had been rebuilt, and it would evidently have not taken more than another twelvemonths, or a total of between three or four years, to restore the mound to its original symmetrical shape and dimensions.

The most remarkable, though by no means the most lofty of the termite edifices peculiar to Australia, are those modifications of these structures which are popularly known by the local titles of "meridian," "magnetic," or "compass" ants' nests. The termitaria belonging to this category are distinguished by their elongate, much compressed contour, comparable in the most evenly constructed examples to huge slabs of undressed sandstone set up on edge. The upper edge or ridge of the "Meridian" termitarium is always the narrower, and is either nearly smooth, irregularly serrated, or may be developed into a series of slender pinnacles. The most notable feature respecting these white ant mounds is, however, the circumstance that the orientation of their longer axis is always coincident with the local parallel of latitude, or, in other words, in a precise line with the north and south points of the magnetic compass.

The most striking examples of these meridian ants nests observed by the writer occur in the Laura Valley, North Queensland, some sixty miles from Cooktown. The altitude of these Laura Valley ant mounds is not very considerable, rarely, indeed, exceeding six or eight 
feet. In accord with the peat-like alluvium out of which they are excavated and constructed, their colour is a dark ashen grey or nearly black. A distinctive feature of these meridian ants' nests is their highly ornate architectural style. They consist of a congeries of slender pinnacles erected close to one another in the same straight line, and which are finally amalgamated. Upon these primary pinnacles numerous subsidiary ones are usuaily constructed. The completed edifice, with its full complement of spires and pinnacles, comes thus when viewed end on, as shown in certain of the photographs taken, to present in miniature a by no means remote resemblance to the architectural pile of some grand cathedral.

A second and simpler form of meridian ants' nest is especially abundant a few miles inland from Port Darwin. It differs from the preceding type in its more massive and less ornate structural plan. The upper edge is nearly smooth or irregularly serrated, but not produced into a series of slender pinnacles. It is further noteworthy, that the environments pertaining to these two meridian varieties differ materially. With the Port Darwin type the habitat affected is that of open grassy plains, while in the Laura Valley form the nest mounds are most abundantly constructed in typical, though thinly wooded forest land.

The raison dêtre of the north and south directions of the longer axial planes, so eminently characteristic of the so-called "Meridian" ants' nests, has given rise to much speculation and a variety of interpretations. By some it is supposed to bear a direct relationship to the prevailing winds. As, however, those in the districts where these ant-hills occur are chiefly south-east or north-west, according to the seasonal monsoon, that interpretation cannot be accepted as satisfactory. To the writer's mind a more probable explanation would appear to present itself in connection with the circumstance that being constructed in this precise meridian line, their larger surface presents the least possibly prolonged exposure to the meridianal ravs of the tropical sun, and that the structures are consequently so built that they shall absorb and retain a minimum amount of solar heat. This question is, however, an interesting one that undoubtedly invites further scientific investigation. The subject of Australian termitaria constitutes, it may be noted, a copiously illustrated chapter in the writer's recently published work, "The Naturalist in Australia."

W. SAVILLE-KENT.

\section{THE LIQUEFACTION OF FLUORINE.}

FLUORINE was prepared for the first time in I 886 by Prof. Moissan, as a product of the electrolysis of anhydrous hydrogen fluoride contained in a platinum apparatus provided with fluorspar stoppers; the new gas was at once found to be the most active chemical substance known, many elements and organic compounds, such as arsenic, antimony, sulphur, iodine, alcohol, and turpentine, immediately and spontaneously bursting into flame when plunged into an atmosphere of fluorine. On mixing the gas with hydrogen, even in the dark, a violent detonation immediately occurs; hydrogen fluoride being produced. The violent action of fluorine upon nearly all substances with which it is brought into contact, obviously renders extremely difficult all experimental work involving the use of the free element. The great manipulative difficulties necessarily arising whilst dealing with the gas on the large scale have, however, been very happily surmounted by Prof. Moissan and Prof. Dewar, who recently described to the Chemical Society the method by which they have succeeded in liquefying fluorine, and determining the more important properties of the liquid substance (Proc. Chem. Soc., November 4, 1897, p. 175). It seemed likely that the great chemical activity of fluorine might so far decrease at low temperatures as to allow of the manipulation of the material in a glass vessel cooled in liquid air ; this was found to be the case.

The fluorine required in the work was prepared by the electrolysis of anhydrous hydrogen fluoride; this liquid being a non-conductor, was made a conductor by dissolving in it potassium fluoride. The liberated fluorine was freed from hydrogen fluoride by being passed first through a platinum worm immersed in a cooling mixture of solid carbon dioxide and alcohol, and subsequently through platinum tubes containing dry sodium fluoride. The purified gas was then passed down a vertical platinum tube fused to the neck of a thin glass bulb which served as the collector, and an exit was provided through a narrower platinum tube contained inside the first. On cooling the apparatus down to $-183^{\circ}$ in boiling oxygen whilst the fluorine is passing through, no liquefaction occurs, but on reducing the pressure under which the oxygen is boiling, and so lowering the temperature to $-185^{\circ}$, the fluorine condenses in the glass bulb to a very mobile yellow liquid; on removing the bulb from the cooling bath the liquid fluorine boils vigorously. Other experiments made with boiling liquid oxygen and liquid air as refrigerating agents indicated that fluorine boils at about - $187^{\circ}$, namely at the boiling point of liquid argon; from this the probable critical temperature and pressure of fluorine are deduced as $-120^{\circ}$ and 40 atmospheres respectively.

At these low temperatures fluorine is without action on glass, and does not displace iodine from iodides; silicon, boron, carbon, sulphur, phosphorus and reduced iron, all of which spontaneously ignite when brought into contact with fluorine at ordinary temperatures, do not inflame if, after being cooled in liquid oxygen, they are plunged into an atmosphere of fluorine. Hydrogen gas inflames spontaneously, with considerable evolution of light and heat, when directed on to the surface of liquid fluorine at $-190^{\circ}$; on passing fluorine on to solidified turpentine cooled by boiling liquid air, a series of explosions occurred resulting in the destruction of the apparatus. It thus seems that the great affinity existing between hydrogen and fluorine is not overcome at - I90. A little liquid fluorine falling on the floor instantly inflames the wood. Fluorine is soluble in liquid oxygen, and on passing in the gas a white flocculent precipitate is formed which, after filtering off, deflagrates violently as the temperature rises; it is possibly a hydrate of fluorine.

Determinations made by floating pieces of various substances in liquid fluorine indicate that its density is about I.I4, and from the invisibility of amber immersed in the liquid the refractive index of the latter would seem to be higher than that of liquid air or oxygen. Liquid fluorine shows no magnetic phenomena when placed between the poles of a powerful electromagnet ; it has a smaller capillarity constant than liquid oxygen, and does not solidify at $-210^{\circ}$. It has no absorption spectrum, and its colour is the same as that of the gaseous element.

W. J. P.

\section{THE LEONID DISPLAY, 1897.}

VERY unfavourable weather appears to have prevented the successful observation of the Leonids at their recent return. In consequence of this the impression seems to have gained ground that the phenomenon did not occur as predicted. This is, however, a mistake. Could those observers who saw so little on the night of the 13 th, have viewed the sky late on the following night, they must have been satisfied at the character of the display. Between about 4.30 and 6 a.m. on Monday morning the 15 th, the usual streak-leaving meteors from Leo became very numerous, and some of them were unusually brilliant, one, which

No. $146_{5}$, VOL. 57$]$ 